\title{
Caligrafias femininas: Marianna e Florbela na letra de Adília
}

\author{
Para a Iná Camargo \\ Maria Lúcia Dal Farra \\ Universidade Federal de Sergipe
}

RESUMO: DA LEITURA DE FLORBELA ESPANCA E MARIANNA ALCOFORADO, ADÍLIA LOPES CRIA UMA POÉTICA CUJOS DOTES LITERÁRIOS TENDEM A EXPLICITAR, PELO AVESSO, UMA POESIA DE MULHER. PRODUÇÃO ELABORADA, NA CONTRAMÃO DAS OBRAS CULTAS, ESCANCARA SUAS FRAGILIDADES ENQUANTO CONQUISTAS REAIS, E SUAS FALTAS COMO COMPETÊNCIAS DE GÊNERO.

ABSTRACT: FROM HER READINGS OF FLORBELA ESPANCA AND MARIANNA ALCOFORADO, ADÍLIA LOPES CREATES HER OWN POETICS WHOSE LITERARY QUALITIES TEND TO EXPLICIT A WOMAN'S POETRY AGAINST THE GRAIN. HER WORK IS MADE AGAINST THE STREAM OF HIGH CULTURE AND, BEING SO, ITS FRAGILITIES ARE WIDE OPEN AS ACTUAL CONQUESTS AND ITS FLAWS AS GENDER SKILLS.

PALAVRAS-CHAVE: POESIA FEMININA - RELEITURA - PARÓDIA KEY-WORDS: FEMININE POETRY - REREADING -PARODY 
dília Lopes, poetisa portuguesa desta última hora, nascida em 1960, possui pelo menos quatro obras que me interessam de perto no que concerne à minha pesquisa atual: O marquês de Chamilly (Kabale und Liebe) (1987), Clube da poetisa morta (1997), Florbela Espanca espanca (1999), Regresso de Chamilly (2000).

Em Clube da poetisa morta e Florbela Espanca espanca, a menção sub-reptícia no primeiro e, no segundo, declarada, diz respeito a Florbela Espanca; nos dois outros livros, O marquês de Chamilly (Kabale und Liebe) e Regresso de Chamilly, é da presença de Marianna Alcoforado que se trata. Portanto, para o meu critério pessoal, tenho em Adília uma poetisa contemporânea que lê Marianna e Florbela, suas coleguinhas numa história feminina da literatura portuguesa, e que as escreve no seu diapasão poético. Mas qual é este?

A caligrafia de Adília é uma das mais enviesadas da atualidade em língua portuguesa. Ela se abastece de duplicidades que produzem propositadamente citações tortas, como é o caso do título desse primeiro livro, que garatuja, por assim dizer assim, o título de um filme de Peter Weir, o Dead Poets Society (de 1989).

Publicado em 1997, o Clube da poetisa morta tem como epígrafe um comentário sobre uma então recente exposição, na BN, acerca do centenário de uma poetisa morta, cujo nome se omite: esta é a forma oblíqua e tortuosa de Adília indicar ali uma alusão silenciosa à poetisa a quem dedicará, mais tarde, um título de livro que, deiticamente identificado, esconde, todavia, nas suas páginas a oblíqua ausência da poetisa que nomeia - que é o que ocorre em Florbela Espanca espanca. Aliás, tanto num livro quanto no outro, é sempre de Adília que se trata, enquanto poetisa morta ou enquanto Florbela Espanca - esta, uma das tantas musas a quem Adília se dispõe a maltratar assim.

Esse é também o caso do subtítulo "(Kabale und Liebe)", de O marquês de Chamilly, que reescreve o título de um drama romântico de Friedriech Schiller, datado de 1784, Amor e intriga, e que fica ali presente justo por estar ausente. A propósito de tais duplicidades que empenam os nomes de livros e de poemas, uma dos mais transtornantes seja talvez a que subjaz a um título de poema existente no Clube da poetisa morta: o "Lúcia no Saldanha em pulgas", que soa por cima do subliminar "Lucy in the sky with diamonds", por cima do inesquecível sucesso dos Beatles.

$\mathrm{O}$ que confere a esta poética um relevo de bricabraque, de ajuntamento pop, de colcha de readymades sem serventia, de paródia que, todavia, não tem nenhuma pretensão de se exercer como tal, pois que toma empréstimos 
apenas com o fito de desaguar no nada e no vazio, desqualificando o original, deteriorando por completo aquilo que lhe serve de referência e sustentação.

Daí também a sua falsa aparência de simplicidade, de discurso oral franciscanamente paratático, descomplicado - a sua pose de berçário sintático. Mas daí também a sua real aparência de complexidade falsa, produzida pela citação erudita (literária, artística, religiosa, cinematográfica, etc); pelo uso de línguas estrangeiras nas epígrafes; pela manipulação do francês ou do latim em meio a poemas em língua portuguesa; pela citação exposta incessante ao desgaste; por juízos consabidos, anexins, parlendas, máximas, sempre corroídos pelo vírus da desconstrução; pela presença de objetos de publicidade, de componentes de consumo, da mídia, esvaziados de significação - por todos esses entraves, que se acumulam minimalistamente nos seus versos ou que sub-repticiamente são invocados em surdina nos seus poemas.

Tais expedientes podem estar tanto a serviço de uma vacuidade de sentido, da mera fruição de um jogo de palavras, de um desembocar impassível num absurdo, da produção de uma pilhéria, de uma patranha, de uma piada oca, quanto servir à disseminação de um tom perverso declarado em extrema singeleza infantil ou em inalterada impassividade - em patético derrisório. Em todo o caso, essa poesia é sempre um desmanche, uma demolição, um abatedor de valores.

Em Clube da poetisa morta (1997), onde as letras são ditas tetras e a gramática uma lógica aplicada; onde a lesma é o lema; onde o poema é a barca do tolo; onde a vida é livro e o livro não é livre; onde o iconoclasta restaura o ícone; onde o poema é o esconjuro do escuro; onde os prêmios literários são estímulos para novos deslizes; onde, quanto a comentários, a poesia e a menarca são parelhas; onde é de ócio e de ódio que se escreve a literatura portuguesa nossa contemporânea - a caligrafia de Adília dissemina ambigüidades e dubiedades a começar pela persistência de versos desabrigados de pontuação e de sinais gráficos, que propiciam a anfibologia e os desvios de sentido.

Os jogos de palavras se expõem aqui de modo mais transparente porque, certamente buscando ampliar o horizonte textual do poema, que é sempre narrativo, se baseiam sobretudo nas relações sonoras obtidas entre os significantes em detrimento de qualquer lógica relativa à realidade. $\mathrm{O}$ interesse de Adília parece ser, pois, o de vasculhar os mecanismos internos da linguagem, a bem dizer, o de testar as relações possíveis entre significantes, sem nenhuma preocupação com as conseqüências que tais ilações puramente fonéticas possam impingir ao significa- 
do, pois que lhe causam danos vigorosos. Melhor dizendo: conta-se justamente com essa dissonância, com tal desequilíbrio entre significante e respectivo significado, para promover uma absoluta desfamiliarização entre linguagem e real. Resulta disso, pois, uma estranheza que expõe, de um lado, os mecanismos de funcionamento da linguagem, e, do outro, as premências de respectiva instauração da realidade - fraturas quase que inconciliáveis por inteiro.

Aliás, metaforicamente, o conselho embutido no poema sobre Clarice Lispector que, entretida com os textos, se esqueceu dos peixes, esclarece tal dissociação: porque, entre um peixe vivo e um texto, deve-se escolher sempre o peixe; vão-se os textos e fiquem os peixes, muito embora diga isso Santo António aos... textos.

Assim, a legislação poética que vigora aqui é a de pretensão de uma autonomia do significante sobre o significado, a da ascendência do parentesco sonoro das palavras, da paronomásia, da aliteração e de outros jogos fonéticos - em prejuízo daquilo que as palavras formulam enquanto representação do real. De maneira que o poema resulta, mercê disso, em paisagem manca, retorcida, desalinhada, ausente de perspectiva, onde os objetos, as coisas, os raciocínios, as especulações padecem de formas de relacionamento interno, de um magnetismo, de um ímã, de um centro de gravidade onde se sustentem. E é nesse sentido que a obra de Adília dá sempre a idéia de que se encontra ainda no forno, na ante-sala de qualquer poética ou comunicação com o leitor, que seus poemas apenas realizam promessas de poesia, produtos ainda descompetentes e imaturos.

Como se não bastasse tal degringolagem, trabalham para subir ainda mais a temperatura desse flagrante vivo de atrito entre gramática e semântica, outros expedientes tais como o uso de medidas diversas dentro de um mesmo corpo poemático, a mudança abrupta de tonalidade e de registro de voz, o surgimento inesperado de uma associação puramente semântica em meio à sonora que vigorava até então; as associações em forma de semiose ilimitada, as rimas inconseqüentes, as enumerações e seqüências caóticas, a mistura de uma contigüidade semântica com entornos estranhos aos signos, a sombra irrevelada de um código outro pairando sobre o que se lê, as constatações inócuas, o recurso constante da narrativa, as substituições absurdas, as querelas em torno de palavras, os anacronismos, os processos ecfrásticos, a miniaturização, as inanidades de vária ordem etc etc etc. 
E, como o desalinhado e desequilibrado remetem culturalmente à concepção do feminino, lembro que, por seu turno, a contingência de mulheres aqui presente é populosa. O clube da poetisa morta é composto em primeiro lugar por Adília, claro está, enquanto emissão lusco-fusco, pois que presente e ausente ao mesmo tempo através dos seus mascaramentos, disfarces e flutuações de pessoa, enquanto poetisa morta e viva, sobre a qual paira a dubiedade da autoria, da assinatura, da entidade misteriosa que assina esse nome. Segue-se à Adília, a sombra centenária de Florbela, Fiama, Clarice Lispector, as Irmãs Cholmondeley, a Lúcia do Saldanha, Marta e Maria, a Eva de Adão, a Tia Paulina, Maria e a Menina Teresa, Sylvie Vartan, Francoise Hardy, Medusa, a personagem do colchão no penteado do soneto de Nicolau Tolentino, a Judite, Dalila, Salomé, Joana D'Arc e Maria Antonieta, a Linda Evangelista, a santa amarrada a uma árvore, a cachorrinha Lassie, Mary Poppins, a Feiticeira do seriado "Casei com uma feiticeira", a Maria de São José, as duas irmãs solteironas e, finalmente, Marianna Alcoforado - que, aliás, comparece num poema em que, ainda presa à clausura, fica submetida às imposições da modernidade.

Assim, supondo que quem bate à porta são as testemunhas de Jeová, vendedores ambulantes ou publicidade, Marianna topa com Chamilly que regressa - poema que anuncia o futuro título do livro de 2000.

Ainda aqui se lê, num poema-piada à maneira daqueles do nosso Modernismo Brasileiro, que o machismo é coisa antiga, da era do Éden, pois que os evangelistas não levaram em conta a hipótese de que Adão, em vez de saudar Eva, a tivesse mandado embora com sete pedras na mão, o mesmo se passando com São José, que correu Nossa Senhora a pontapé.

$\mathrm{E}$ a questão do feminino invade, com igual ímpeto, o livro de 1999, o Florbela Espanca espanca. A começar pela epígrafe de Lucy Elmman, que afirma haver no mundo homens "who fuck you tenderly in the dark"... E se torna veemente, logo no primeiro poema, que toma, de Florbela, apenas a tonalidade maior, para proclamar a declaração de cio que testa as conquistas e os limites da revolução, revolução que se faz, segundo tais versos, no banheiro da casa, da escola e do trabalho.

O clamor de igualdade entre homem e mulher comparece imediatamente na peça em que Adília se declara não ser mais nem menos que ninguém, inclusive os animais. Sylvia Plath, que não sabe cozinhar e a quem as crianças deprimem, é também para aqui chamada: a mulher tem de pensar em tudo, das panelas aos preservativos, quando tudo o que se quer é um pouco 
de privacidade - descalçar os sapatos no escurinho do cinema ou conhecer, segundo Barthes, o dedo próprio para a masturbação. Aliás, só para homem funciona a máxima pseudocartesiana "desejo, logo sou". No caso da mulher, "desejar" significa um "nunca mais acabar de ser".

O senso demográfico feminino desta obra é, pois, composto por Florbela, Sylvia Plath e Lucy Elmman, seguidas por um enorme elenco: por Claudia Schiffer, por uma trapezista, pelas mulheres da Escola de Fontainebleau, pela pintora, pela moça chorosa do quadro de De Launay, pela Janeth Leigh de Hitchcock, pelas flamengas de Jacques Brel, pela raposa, pela galinha, pela ceifeira de Pessoa, pela gestora, pela menina da sua mãe, pelas fariséias, pela pequena, por Enid Blyton, por Marianna Alcoforado, por Maria Aliete Galhoz, por Dona Rosinha, por Maria Arminda, pela cadela e pelas lagartixas - supondo que estas últimas sejam todas fêmeas.

Neste livro, em que não se sabe bem quem espanca quem, Adília também nos premia com diferentes definições sobre um rol de coisas: sobre a escrita, sobre o amor, sobre Deus, sobre a obra de arte, sobre o livro, sobre a vida, sobre aquilo que a torna poetisa. Sabemos, por meio dele, que um poema não é uma mala, mas um mal-entendido; que os portugueses são gente ousada ou usada; que quando a vida é madrasta a arte não basta; que um tio bispo não resolve o problema de Dom Sebastião; que o poema mau não mata; que para escrever é preciso ter pouco o que fazer; que a vida é ação de graças; que escrever é lutar com o Anjo; que haverá ressurreição dos livros; que o escritor é às vezes um estupor - e que é preciso dinheiro para escrever...

Em que preciso momento Florbela é aqui tangenciada? Quem sabe já a partir desta última constatação... Também a solidão do poema em francês sobre a família estranha e bizarra ("plus proches de moi sont les cafards") - menciona uma marcada melancolia na história da poesia portuguesa. No poema "Dois ciprestes", na pergunta lançada acerca do lugar em que será atado aquilo que nunca foi atado na terra - também ecoa uma insistente marca florbeliana, a do desacerto amoroso que, no caso de Adília, se resolve facilmente pela suposição de que há, no céu, um duplex para tais tipos de amantes desencontrados. Também o derradeiro poema, "O enterro de Dona Rosinha", lembra desfocadamente, pelo entrecho, um conto de Florbela, "O crime do Pinhal do Cego", onde há, por sinal, uma personagem com esse mesmo nome. Mas mais vigoroso no poema é o incisivo acento telúrico, este sim, de lavra florbeliana. 
Se o soneto "Eu quero amar, amar perdidamente" é aqui invocado pela temperatura indubitável de uma proclamação de direitos femininos, a poética de Adília parece se prender mais, quero crer, aos versos finais desse poema. Seguindo, talvez, o conselho da musa que espanca, Adília procura se perder... para se encontrar. Porque é do deterioramento, do desconvergência dos versos de Florbela, que Adília produz a sua obra. Os poemas de Florbela quanto, aliás, a obra de quaisquer outros autores - sejam eles poetas, pintores, críticos, romancistas, escultores, diretores de cinema, compositores, etc - só servem para desencadear em Adília o ímpeto da desapropriação - o mais profundo cerne da sua caligrafia poética.

Daí que a declaração de princípios que se lê como portal deste Florbela Espanca espanca venha confirmar, pelo avesso, a desidentidade que nomeia Adília Lopes: "Este livro/ foi escrito/ por mim" - onde este "mim" é uma comunidade; é, na verdade, o próprio clube da poetisa morta, composto, neste caso, para além dos já citados, também por Van Gogh, Manet, Horácio, Jacques Tourneur, Proust, Camões, Mário Cesariny de Vasconcelos, Mallarmé, Lorca, bem como pelos tantos outros seres infinitesimais que não estão aqui explicitados.

Assim, em lugar da emoção florbeliana, Adília cultiva a impassibilidade e a derrisão; em lugar do fecho de ouro dos sonetos de Florbela, Adília pratica o esvaimento final do poema, a murchidão, o desaponto que leva ao absurdo.

Mas tais dotes poéticos, em lugar de trabalharam negativamente, demonstram a sua face mais louvável: a de que se trata de uma poesia de mulher esta de Adilia Lopes. Favor reparar como esta poética se exerce propositadamente como a metáfora do elenco de atributos culturais conferidos à condição feminina.

Adília realiza, pois, na contramão das outras poéticas cultas e acatadas da pós-modernidade, uma poesia de menor-de-idade, carente de excelência e de perfeição, modelo de segunda mão, criado a partir de uma costela alheia, poesia de simplicidade infantil, ligada aos rudimentos da gramática, à préobra, ao pré-poema. Ela se deixa morrer na praia, ela mostra as suas traseiras. Adília permite que transpareçam, sem pejo, todos os princípios elementares que estão na base da produção poética - as associações sonoras e semânticas, as rimas, a linearidade gramatical, a ambigüidade contida no aproveitamento semântico dos equívocos de linguagem, a paronomásia, os jogos de palavras. Na sua obra, a causa dispensa o efeito, o fundamento despede a crença, a premissa não se interessa pela conclusão, o motivo não diz respeito à ação. 
Pode-se dizer que, sem pudor, ela alça o parasitismo, a paródia, a citação alheia e a colagem ao grau de atributo o mais valioso, revelando a sua identidade poética por meio de equívocos, desconcertos, absurdos, descompetências, faltas de nexo - de erros diante do original; maneira de Adília, como mulher, acertar na medida em que vai errando. Também o uso da entropia enquanto imprevisibilidade da informação, como conteúdo imperscrutável, comparece como dote historicamente feminino, assim como a performatividade e a inexistência de autoria, a falta de assinatura - identificando o feminino enquanto buraco negro, como o não-todo lacaniano.

Em O regresso de Chamilly (2.000), a citação do Gênesis relativa à criação da mulher se encontra logo nas portadas do livro, na última das epígrafes. E essa alusão direta vai comparecer paródica e diretamente em pelo menos 5 das 24 peças que compõem o livro, incluindo uma alongada "Nota da Autora", que considera que esta obra pertence ainda a um "marialvismo de fundo", o que não a torna fã da sua própria obra. Por isso mesmo despede-se do leitor acenando com a promessa de escrita de um novo livrinho sobre Chamilly.

O fato é que, nos referidos poemas - e desde cedo se sabe que "a vida é barroca" - Marianna e Chamilly se prestam à zombaria sobre o casal bíblico, submetido aos desgastes domésticos, às intempéries da pós-modernidade e aos hábitos burgueses, passeando pelo pomar não mais paradisíaco, fazendo amor sobre a atualidade das notícias dos jornais - dando, enfim, adeus ao imaginário, ou “à Dieu” ou “au diable l'Imaginaire!". Anacronismo é, pois, aqui a palavra de ordem que cria o mito da Bela Adormecida ao contrário ou o da Bela Desperta, em associações espúrias com o mito bíblico da criação da mulher, estabelecendo liames entre Castelo e Convento, entre aristocracia e igreja, cujo túnel secreto da passagem subterrânea pode vir a ser interditado.

Em todo o caso, como se trata de discorrer sobre a aliança carnal entre Adão e Eva, entre cadela e cão, entre Marianna e Chamilly, a divisa desta "Art poétique" de Adília declara: "De l'amour avant toute chose".

Os jogos de palavras continuam e agora trabalham na decomposição de fatores - coincidentemente o título do poema final traduzido por Adília. Assim, Chamilly se decompõe em Chá e em Milly, aparentemente dois chats, dois gatos; Chamilly, que já deu Milly, também dá Mily Possoz que, aliás, pinta o retrato do casal no pomar idílico. Por seu turno, a população femini- 
na é ocupada quase toda com Marianna e Adília, para além de Mily Possoz, Sylvia Plath, Virginia Woolf e Agustina.

Já O marquês de Chamilly (Kabale und Liebe) (1987) parece se assentar como um tratado sobre o ócio de Mariana à espera de Chamilly, o que remete, de cara, à crítica sobre a força de produção feminina, transformando o espaço feminino numa espécie de "rincão perverso" baudelaireano - expressão que o poeta francês utiliza para designar a tela de Delacroix, cuja mulher de Argel, Adília compara à Marianna quando esta constata em Chamilly o seu gigolô. Ufa!

Tais mediações alongadas são propositais da minha parte, pois que explicitam aqui o mecanismo por meio do qual se nomeia alguma coisa. Refiro-me à tática do viés, que passa por Schiller e, por decorrência, por Verdi (pela Luisa Müller), por Bach, Camões, Shakespeare, pelo latim (Vergílio? Pelos Carmina Burana?), pelo francês, por variegadas citações, por fakes, enfim, desembocando num poema barroco-concretista em latim que desenha tanto a figura de uma cruz patriarcal quanto a da genitália masculina.

E com tal marco fincado sobre o encerramento do livro, a simbólica de Mariana se esclarece. Da cruz e do sexo ela tece o seu ócio na cela do convento, de onde não se vê Mértola.

Mas tais figuras remetem também ao marco do correio, emblemática da comunicação de Mariana com Chamilly, de Adília com seus leitores. Anacronismos, inconclusões, nonsenses, derivações insólitas, dubiedades, miniaturizações, duplicações, substituições inusitadas, esvaimento final dos poemas. Os jogos de palavras também proliferam aqui: Chamilly e chantilly; Alcoforado e alcachofra; duchesses e duquesas. Escrever cartas passa a ser, aqui, uma ameaça; não recebê-las transtorna a higiene pessoal...

Assim, o que há sobretudo, tanto na epistolografia entre Mariana e o Marquês, quanto na relação entre Adília e seus leitores é um desvio de comunicação, de que o poema que leio dá dupla conta, visto que catalisa o procedimento poético desta obra que venho desdobrando para vocês. Falo aqui de um deslocamento de interlocução, de desencontro de comunicação, de súbitos saltos de registro de fala, de veio humorístico, de imprevisibilidades e distúrbios, do fake, da paródia, do arruinamento e da deterioração da obra alheia, da dupla orientação de escrita, das fraturas sublinhadas, do resultado perverso e derrisório das inconclusões que desmancham a identidade de uma emissão de voz. Tal poesia, como se vê, só uma mulher ousaria escrever... 


\title{
O marquês de Chamilly a Marianna Alcoforado
}

\author{
Minha senhora deve ter \\ uma coisa muito urgente e capital \\ a dizer-me \\ porque me tem escrito muito \\ e muitas vezes \\ porém lamento dizer-lho \\ mas não percebo \\ a sua letra \\ já mostrei as suas cartas \\ a todas as minhas amigas \\ e à minha mãe \\ e elas também não percebem bem \\ não me poderia dizer \\ o que tem a dizer-me \\ em maiúsculas? \\ ou pedir a alguém \\ com uma letra mais regular \\ que a sua \\ que me escreva \\ por si? \\ como vê tenho a maior boa vontade \\ em lhe ser útil \\ mas a sua letra minha senhora \\ não a ajuda
}

\section{Referência Bibliográfica}

LOPES, Adília. Obra (com três gravuras originais de Paula Rego e posfácios de Elfriede Engelmayer e de Américo António Lindeza Diogo). Lisboa: Mariposa Azul, 2000 . 